\title{
Predictive factors and prognosis for recurrent laryngeal nerve invasion in papillary thyroid carcinoma
}

This article was published in the following Dove Press journal:

OncoTargets and Therapy

II September 2017

Number of times this article has been viewed

\author{
Wenjie Chen' \\ Jianyong Lei' \\ Jiaying You ${ }^{2}$ \\ Yali Lei ${ }^{3}$ \\ Zhihui Li ${ }^{1}$ \\ Rixiang Gong' \\ Huairong Tang ${ }^{3}$ \\ Jingqiang Zhu' \\ 'Thyroid and Parathyroid Surgery \\ Center, ${ }^{2}$ West China School of \\ Clinical Medicine, ${ }^{3} \mathrm{Health}$ and \\ Management Center, West China \\ Hospital of Sichuan University, \\ Chengdu, People's Republic of China
}

Correspondence: Huairong Tang Health and Management Center, West China Hospital of Sichuan University, No 37 Guo Xue Xiang, Chengdu 61004I, People's Republic of China

Tel/fax +86288542 2933

Email thrhuaxilI@I63.com
Background: Recurrent laryngeal nerve (RLN) invasion in papillary thyroid carcinoma (PTC) is one of the main predictors of poor prognosis. The present study investigated the risk factors for RLN invasion in PTC patients.

Methods: A total of 3,236 patients who received thyroidectomy due to PTC in Thyroid and Parathyroid Surgery Center of West China Hospital of Sichuan University were reviewed. Demographics and clinical factors, imaging examination (ultrasonography) characteristics, surgical details, postoperative pathological details, recurrence, and postoperative complications were recorded. Univariate and multivariate analyses were used to study the risk factors of RLN invasion, Kaplan-Meier method was performed to compare the outcomes of tumor recurrence.

Results: Patients with RLN invasion had a higher recurrence rate than those in the control group $(p<0.001)$. Multivariate analyses showed that age greater than 45 years $(p<0.001)$, a largest tumor size bigger than $10 \mathrm{~mm}(p<0.001)$, clinical lymph node metastasis (cN1) $(p<0.001)$, posterior focus ( $p<0.001)$, extrathyroidal extension $(p<0.001)$, esophageal extension $(p<0.001)$, tracheal extension $(p<0.001)$, and preoperative vocal cord paralysis $(p<0.001)$ were independent predictors for RLN invasion.

Conclusion: PTC patients with RLN invasion have a negative prognosis and a higher recurrence rate. Meticulous operation and careful follow-up of patients with the above factors is recommended.

Keywords: papillary thyroid carcinoma, recurrent laryngeal nerve invasion, predictive factors, lymph node metastases, Hashimoto's thyroiditis

\section{Introduction}

Papillary thyroid carcinoma (PTC) is the most common thyroid cancer, and its morbidity rate has dramatically increased in recent decades. ${ }^{1,2}$ Although patients with PTC have a good prognosis, ${ }^{3}$ some patients still have a poorer quality of life when PTC invades the adjacent organs and structures, which may cause corresponding symptoms and increase the difficulty of complete surgical resection, ${ }^{4}$ especially when the invasion occurs in the recurrent laryngeal nerve $(\mathrm{RLN}) .{ }^{5,6} \mathrm{RLN}$ is alongside the trachea and adjacent the posterior thyroid layer, which is one of the most commonly infiltrated organs in locally invasive thyroid carcinoma. ${ }^{7}$

Preoperative vocal cord laryngoscopy and voice examination are routinely used to identify the preoperative function of the $\mathrm{RLN},{ }^{8}$ but it is insufficient to detect the RLN invasion, and may miss some local RLN invasion cases which do not lead to pronounced vocal cord paralysis. ${ }^{6,7,9}$ Therefore, it is necessary to determine which factors can influence RLN invasion. In this study, we analyze the risk factors and 
prognosis of PTC with RLN invasion so that surgeons can choose the best treatment strategy.

\section{Methods}

From May 2009 to August 2015, patients who underwent surgical treatment at the Department of Thyroid and Parathyroid Surgery Center in West China Hospital of Sichuan University were retrospectively reviewed. The inclusion criteria were no history of thyroid or neck surgery and PTC confirmed by paraffin section after surgery. The exclusion criteria were presence of other tumors or missing clinical data that may severely influence the statistical results. Ultimately, 3,236 PTC patients were included in our study. Of these, 105 patients had confirmed RLN invasion by primary tumor or lymph node metastases (LNM) and were defined as invasion group, the remaining 3,131 patients were defined as control group. RLN invasion was defined as positive intraoperative findings or cryosection confirming obvious invasion of the RLN by the primary tumor or LNM. ${ }^{6}$

Data were collected for patients' demographics, preoperative and postoperative imaging examination (ultrasonography) characteristics, surgical details, postoperative pathological details, tumor recurrence, and postoperative complications.

The primary endpoints of this study were to evaluate the risk factors of RLN invasion. The secondary endpoints were to evaluate the prognosis in the two groups and the effect of different operations on RLN invasion. This study was approved by the Institutional Review Board of West China Hospital of Sichuan University, and signed consent was obtained from all patients.

All patients underwent preoperative ultrasonography (including both thyroid gland and neck lymph nodes [II-VII levels]) to evaluate the primary tumor and LNM; fine needle aspiration of the thyroid nodule was conducted to diagnose PTC preoperatively, and preoperative vocal cord laryngoscopy was routinely performed to evaluate the function of RLN.

All surgeries were performed by three experienced surgeons in our department. The resection range was based on tumor diameter, location, invasion, lymph node metastasis, distant metastasis, and patients' desires. Ipsilateral lobe plus isthmic resection with ipsilateral central neck dissection was the minimum resection range. Lateral neck dissection was implemented only when preoperative fine needle aspiration cytology or intraoperative frozen sections confirmed lateral node metastases. Intraoperative nerve monitoring was used to prognosticate postoperative RLN function. We recorded the electrical signals before and after thyroid gland dissection and after central neck dissection to evaluate the functional changes of RLNs. Primary treatment of RLN invasion involved maximum resection of the tumor while maximally preserving the function of the RLN. Patients with RLN invasion underwent partial layer resection ${ }^{10}$ until the frozen section cytology of the marginal samples was confirmed negative. If partial layer resection was not complete, surgeons resected the invasive RLN and then made an anastomosis between the two segments of RLN or between the RLN and the ansa cervicalis. If the above methods were not feasible, the surgeon simply resected the invasive RLN.

Continuous data are represented as the mean \pm standard deviation. Student's $t$-test was used to compare continuous variables, while the $\chi^{2}$ test or Fisher's exact test was used for categorical variables. Logistic regression was used for multivariable analysis. Kaplan-Meier method was used to analyze the outcomes of tumor recurrence. SPSS software (SPSS 20; SPSS Inc., Chicago, IL, USA) was used for statistical analysis. $p<0.05$ was considered statistically significant.

\section{Results \\ Patients' baseline characteristics and pathology}

A total of 3,236 patients who underwent primary surgical treatment in our center during the period between May 2009 and August 2015 were retrospectively reviewed. Of these, 105 patients with RLN invasion were selected as invasion group in our study, and their clinical and pathologic characteristics are listed in Table 1. Patients in the invasion group were older than those in the control group (mean age, $50.4 \mathrm{vs}$ 42.3 years; $p<0.001)$. The largest tumor size in the invasion group was larger than that in the control group (mean size, 26.0 vs $12.4 \mathrm{~mm} ; p<0.001)$. The sex ratio between the two groups showed no significant difference $(p=0.381)$.

In the invasion group, preoperative laryngoscopy confirmed that vocal cord paralysis occurred in 28 patients (26.7\%), and of these patients only $8(28.6 \%)$ had preoperative voice changes. In the control group, only 1 patient was confirmed to have vocal cord paralysis by preoperative laryngoscopy. This patient had a massive goiter, and the postoperative pathological results were PTC with nodular goiter, and the vocal cord paralysis in this patient had been restored after surgery.

In the invasion group, extrathyroidal, esophageal, and tracheal extension were observed in 103 (98.1\%), 30 (28.6\%), and $36(48.6 \%)$ patients, respectively. Furthermore, clinical lymph node metastasis ( $\mathrm{cN}$ ) showed cN0 (45 cases, 43.4\%), cN1a (11 cases, 10.4\%), and cN1b (49 cases, 46.2\%) status. 
Table I Associations between clinicopathological characteristics and PTC patients with or without RLN invasion

\begin{tabular}{|c|c|c|c|}
\hline $\begin{array}{l}\text { Preoperative } \\
\text { features }\end{array}$ & $\begin{array}{l}\text { Invasion group } \\
(n=105)\end{array}$ & $\begin{array}{l}\text { Control group } \\
(n=3,|3|)\end{array}$ & $\begin{array}{l}\text { Univariate } \\
\text { ( } p \text {-value) }\end{array}$ \\
\hline Age (y) & $50.4 \pm 13.8$ & $42.3 \pm 12.1$ & $<0.001$ \\
\hline$\leq 45$ & 35 & 1,919 & \\
\hline$>45$ & 70 & 1,212 & $<\mathbf{0 . 0 0 1}$ \\
\hline \multicolumn{4}{|l|}{ Sex } \\
\hline Male & 38 & 1,006 & \\
\hline Female & 67 & 2,125 & 0.381 \\
\hline Height (cm) & $162.3 \pm 7.1$ & $163.6 \pm 7.7$ & 0.098 \\
\hline Weight (kg) & $63.0 \pm 11.5$ & $63.0 \pm 12.4$ & 0.972 \\
\hline BMI $\left(\mathrm{kg} / \mathrm{m}^{2}\right)$ & $24.0 \pm 3.4$ & $23.5 \pm 4.90$ & 0.314 \\
\hline \multicolumn{4}{|c|}{ Unilateral multifocality } \\
\hline No & 90 & 2,595 & \\
\hline Yes & 15 & 536 & 0.511 \\
\hline \multicolumn{4}{|l|}{ Bilaterality } \\
\hline No & 72 & 2,327 & \\
\hline Yes & 33 & 804 & 0.186 \\
\hline \multicolumn{4}{|l|}{ PTC variant } \\
\hline Follicular & 0 & 17 & \\
\hline Conventional & 105 & 3,114 & 0.449 \\
\hline \multicolumn{2}{|l|}{ size $(\mathrm{mm})$} & $12.4 \pm 7.5$ & $<\mathbf{0 . 0 0 1}$ \\
\hline$\leq 10$ & 13 & 1,662 & \\
\hline$>10$ & 92 & 1,469 & $<0.001$ \\
\hline \multicolumn{4}{|l|}{$N$ stage } \\
\hline cNO & 45 & 2,790 & \\
\hline $\mathrm{cNI}$ & 60 & 341 & $<\mathbf{0 . 0 0 I}$ \\
\hline \multicolumn{4}{|c|}{ Tumor longitudinal location } \\
\hline Superior & 23 & 562 & \\
\hline Median & 49 & 1,223 & \\
\hline Inferior & 30 & 1,286 & \\
\hline Isthmic & 3 & 60 & 0.072 \\
\hline \multicolumn{4}{|c|}{ Tumor sagittal location } \\
\hline Anterior & 52 & 2,457 & \\
\hline Posterior & 53 & 674 & $<\mathbf{0 . 0 0 1}$ \\
\hline \multicolumn{4}{|c|}{ Extrathyroidal extension } \\
\hline No & 2 & 1,639 & \\
\hline Yes & 103 & 1,492 & $<\mathbf{0 . 0 0 1}$ \\
\hline \multicolumn{4}{|c|}{ Esophageal extension } \\
\hline No & 75 & 3,070 & \\
\hline Yes & 30 & 61 & $<\mathbf{0 . 0 0 1}$ \\
\hline \multicolumn{4}{|c|}{ Tracheal extension } \\
\hline No & 54 & 3,031 & \\
\hline Yes & 51 & 100 & $<0.001$ \\
\hline \multicolumn{4}{|l|}{ NG } \\
\hline No & 44 & 1,490 & \\
\hline Yes & 61 & $|, 64|$ & 0.251 \\
\hline \multicolumn{4}{|l|}{ HT } \\
\hline No & 90 & 2,049 & \\
\hline Yes & 15 & 1,082 & $<0.001$ \\
\hline \multicolumn{4}{|c|}{ Pre-vocal cord paralysis } \\
\hline No & 77 & 3,130 & \\
\hline Yes & 28 & I & $<\mathbf{0 . 0 0 1}$ \\
\hline \multicolumn{4}{|l|}{ Pre-hoarseness } \\
\hline No & 97 & 3,130 & \\
\hline Yes & 8 & I & $<0.001$ \\
\hline
\end{tabular}

Note: Bold figures indicate $p<0.05$ which were considered statistically significant. Abbreviations: RLN, Recurrent laryngeal nerve; PTC, Papillary thyroid carcinoma; BMI, body mass index; $\mathrm{cN}$, clinical lymph node metastasis; NG, nodular goiter; HT, Hashimoto's thyroiditis; Pre-vocal cord paralysis, preoperative vocal cord paralysis; Pre-hoarseness, preoperative hoarseness.

\section{Univariate and multivariate analyses of} risk factors for recurrence

Univariate analysis (Table 1) showed that age greater than 45 years $(p<0.001)$, the largest tumor size bigger than $10 \mathrm{~mm}$ $(p<0.001)$, cN1 $(p<0.001)$, posterior focus $(p<0.001)$, extrathyroidal extension $(p<0.001)$, esophageal extension $(p<0.001)$, tracheal extension $(p<0.001)$, absence of Hashimoto's thyroiditis $(p<0.001)$, preoperative vocal cord paralysis $(p<0.001)$, and preoperative hoarseness $(p<0.001)$ were significantly associated with a high prevalence of RLN invasion.

In multivariate analysis (Table 2), age greater than 45 years (odds ratio [OR]: 4.958, $p<0.001$ ), a largest tumor size bigger than $10 \mathrm{~mm}$ (OR: $15.853, p<0.001)$, $\mathrm{cN} 1$ (OR: 12.520, $p<0.001$ ), posterior focus (OR: 5.328, $p<0.001$ ), extrathyroidal extension (OR: 97.662, $p<0.001$ ), esophageal extension (OR: 7.381, $p<0.001$ ), tracheal extension (OR: 25.885, $p<0.001$ ), and preoperative vocal cord paralysis (OR: 1,600.100, $p<0.001$ ) were independent predictors for RLN invasion.

\section{Surgical complications and postoperative recovery}

Of the 105 patients in the invasion group, 82 (78.1\%) patients underwent autologous parathyroid transplantation. Temporary and permanent hypocalcemia occurred in $68(64.8 \%)$ and $4(3.8 \%)$ patients, respectively. Besides, the proportion of patients with bleeding, chyle leakage, esophageal fistula, tracheal fistula, and infection were different between the invasion group and the control group, but these differences did not reach statistical significance (Table 3).

To comprehensively estimate the postoperative situation between two groups, postoperative hospital stay, drainage volume, and overall hospitalization costs were evaluated and compared. As shown in Table 3, the length of the postoperative hospital stay was longer in the RLN invasion group (9.3 \pm 9.6 days) than in the control group (5.6 \pm 2.4 days), and this difference showed statistical significance $(p<0.001)$. Meanwhile, costs were higher for patients in the invasion group $(\$ 4,012.8 \pm \$ 1,839.8)$ than in the control group $(\$ 3,496.8 \pm \$ 756.7)$, and this difference also reached statistical significance $(p=0.005)$.

\section{Follow-up for recurrence}

Kaplan-Meier analysis of predictive recurrence-free survival (RFS) was made between the two groups (Figure 1). The median follow-up period was 32 months (range 12-96 months). Tumor recurrence occurred in $33(31.4 \%)$ patients of the 
Table 2 Multivariate Logistic Regression for risk factors for RLN invasion in PTC

\begin{tabular}{|c|c|c|c|}
\hline $\begin{array}{l}\text { Preoperative } \\
\text { features }\end{array}$ & OR & $\begin{array}{l}95 \% \text { confidence } \\
\text { interval }\end{array}$ & $p$-value \\
\hline \multicolumn{3}{|l|}{ Age (y) } & $<0.001$ \\
\hline$\leq 45$ & Ref & & \\
\hline$>45$ & 4.958 & $2.572-9.557$ & \\
\hline \multicolumn{3}{|c|}{ Largest tumor size (mm) } & $<0.001$ \\
\hline$\leq 10$ & Ref & & \\
\hline$>10$ & 15.853 & $6.595-38.105$ & \\
\hline \multicolumn{3}{|l|}{$\mathrm{N}$ stage } & $<0.001$ \\
\hline cNO & Ref & & \\
\hline $\mathrm{cNI}$ & 12.520 & $6.191-25.321$ & \\
\hline \multicolumn{3}{|c|}{ Tumor sagittal location } & $<0.001$ \\
\hline Anterior & Ref & & \\
\hline Posterior & 5.328 & $2.618-10.840$ & \\
\hline \multicolumn{3}{|c|}{ Extrathyroidal extension } & $<0.001$ \\
\hline No & Ref & & \\
\hline Yes & 97.662 & || $.882-802.73 \mid$ & \\
\hline \multicolumn{3}{|c|}{ Esophageal extension } & $<0.001$ \\
\hline No & Ref & & \\
\hline Yes & 7.381 & $2.967-18.362$ & \\
\hline \multicolumn{3}{|c|}{ Tracheal extension } & $<0.001$ \\
\hline No & Ref & & \\
\hline Yes & 25.885 & II.833-56.626 & \\
\hline \multicolumn{3}{|l|}{ HT } & 0.098 \\
\hline No & Ref & & \\
\hline Yes & 0.442 & $0.169-1.161$ & \\
\hline \multicolumn{3}{|c|}{ Pre-vocal cord paralysis } & $<0.001$ \\
\hline No & Ref & & \\
\hline Yes & $1,600.100$ & $|22.030-20,98| .050$ & \\
\hline \multicolumn{3}{|l|}{ Pre-hoarseness } & 0.770 \\
\hline No & Ref & & \\
\hline Yes & 0.560 & $0.012-27.232$ & \\
\hline
\end{tabular}

Note: Bold figures indicate $p<0.05$ which were considered statistically significant. Abbreviations: RLN, Recurrent laryngeal nerve; PTC, Papillary thyroid carcinoma; $\mathrm{OR}$, odds ratio; cN, clinical lymph node metastasis; HT, Hashimoto's thyroiditis; Pre-vocal cord paralysis, preoperative vocal cord paralysis; Pre-hoarseness, preoperative hoarseness; Ref, reference.

Table 3 Postoperative complications and recovery of the two patient groups

\begin{tabular}{|c|c|c|c|}
\hline Complications & $\begin{array}{l}\text { Invasion } \\
\text { group }(n=105)\end{array}$ & $\begin{array}{l}\text { Control } \\
\text { group }(n=3,131)\end{array}$ & $p$-value \\
\hline $\begin{array}{l}\text { Postoperative hospital } \\
\text { stay (days) }\end{array}$ & $9.3 \pm 9.6$ & $5.6 \pm 2.4$ & $<0.001$ \\
\hline $\begin{array}{l}\text { Postoperative drainage } \\
\text { volume }\end{array}$ & $450.4 \pm 429.1$ & $384.0 \pm 249.1$ & 0.116 \\
\hline $\begin{array}{l}\text { Overall hospitalization } \\
\text { costs (dollar) }\end{array}$ & $4,0 \mid 2.8 \pm 1,839.8$ & $3,496.8 \pm 756.7$ & 0.005 \\
\hline $\begin{array}{l}\text { Autologous parathyroid } \\
\text { transplantation (yes) }\end{array}$ & $82(78.1 \%)$ & $2,629(84.0 \%)$ & 0.108 \\
\hline Temporary hypocalcemia & $68(64.8 \%)$ & $2,164(69.1 \%)$ & 0.343 \\
\hline Permanent hypocalcemia & $4(3.8 \%)$ & $58(1.9 \%)$ & 0.281 \\
\hline Bleeding & $0(0 \%)$ & $6(0.2 \%)$ & 0.653 \\
\hline Chyle leakage & $2(1.9 \%)$ & $43(1.4 \%)$ & 0.973 \\
\hline Esophageal fistula & $0(0 \%)$ & $3(0.1 \%)$ & 0.751 \\
\hline Tracheal fistula & I (0.95\%) & $5(0.2 \%)$ & 0.063 \\
\hline Infection & I (0.95\%) & $13(0.4 \%)$ & 0.409 \\
\hline
\end{tabular}

Note: Bold figures indicate $p<0.05$ which were considered statistically significant.

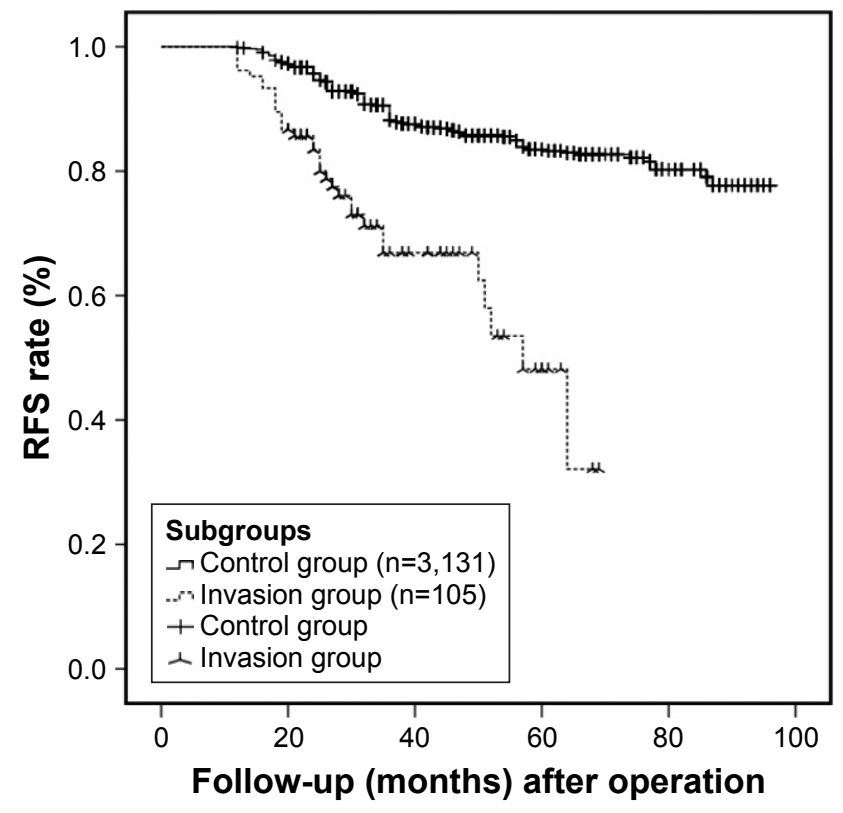

Figure I The graph shows the predictive recurrence-free survival (RFS) in invasion group and control group.

Note: The difference between the two groups was significant $(p<0.00 \mathrm{I})$

RLN invasion group and $321(10.3 \%)$ patients of the control group. There were no deaths from tumor recurrence, and the tumor recurrence rates in the two groups were significantly different $(p<0.001)$.

To compare the predictive RFS among different surgical methods in the invasion group, Kaplan-Meier analysis was also performed in different surgical method subgroups. As shown in Table 4, 67 patients underwent partial layer resection and 38 patients underwent resection or reconstruction. There were no significant differences in predictive RFS between the two subgroups (Figure 2, $p=0.743$ ); the median follow-up period was 28 months (range 12-69 months).

\section{Discussion}

According to the Risk of structural disease recurrence in the revised 2015 ATA Guidelines, the risk of recurrence in patients with gross extrathyroidal extension ranges from $23 \%$ to $40 \% .{ }^{11}$ The RLN is a branch of the vagus nerve that innervates all laryngeal muscles except the cricothyroid muscle. It possesses anatomic proximity to the thyroid gland, and in locally invasive thyroid carcinoma, RLN is one of the most

Table 4 Surgical management of invasion group and the situation of recurrence in different subgroups

\begin{tabular}{lll}
\hline & $\begin{array}{l}\text { Partial layer } \\
\text { resection } \\
(\mathbf{n}=\mathbf{6 7})\end{array}$ & $\begin{array}{l}\text { Resection or } \\
\text { reconstruction } \\
(\mathbf{n}=\mathbf{3 8})\end{array}$ \\
\hline Recurrence & 15 & 7 \\
Nonrecurrence & 52 & 31 \\
\hline
\end{tabular}




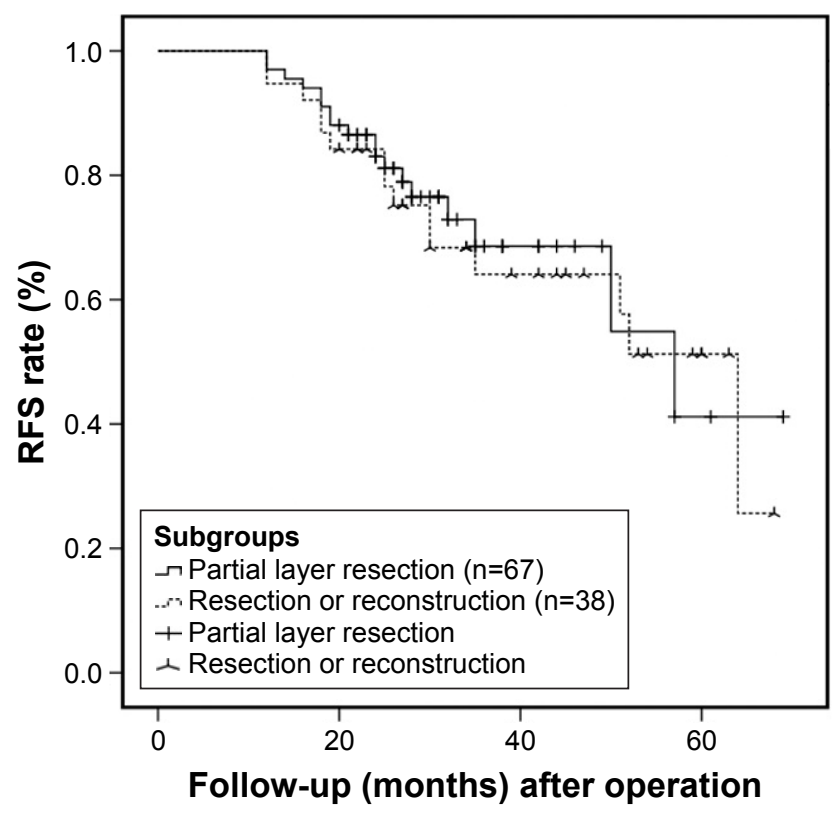

Figure $\mathbf{2}$ The graph shows the predictive recurrence-free survival (RFS) in different surgical method subgroups of invasion group.

Note: No significant difference was found between partial layer resection group and resection or reconstruction group $(p=0.743)$.

commonly involved structures. The rate of RLN invasion can reach to $47 \%,{ }^{7}$ and the dysfunction of the RLN will lead to an indifferent quality of life. ${ }^{12}$ In addition, preoperatively confirmed vocal cord paralysis is a signal for the invasion of thyroid cancer, ${ }^{13}$ many such patients' upper aerodigestive tracts have also been invaded by neoplasma, ${ }^{14}$ which may increase the difficulty of complete surgical resection and always leads to a negative prognosis.

Preoperative vocal cord laryngoscopy and voice examination are routinely used and are important methods to identify the preoperative function of the RLN, ${ }^{8}$ but RLN dysfunction could be caused not only by invasion of a malignant tumor but also by the oppression of a massive goiter. ${ }^{7,9,15}$ In addition, not all RLN invasions will lead to vocal cord paralysis, especially when the RLN is infiltrated by lymph nodes, ${ }^{6,7,9}$ and some patients with a unilateral paralyzed vocal cord will not present clear voice changes due to the gradual compensatory function by the contralateral vocal cord. ${ }^{7,16}$ Another study ${ }^{17}$ indicated that MRI is a useful method to predict RLN invasion, but this method is limited by the thyroid tumor's size and the location of RLN invasion. In this present study, we found age greater than 45 years, a largest tumor size bigger than $10 \mathrm{~mm}, \mathrm{cN} 1$, posterior focus, extrathyroidal extension, esophageal extension, tracheal extension, and preoperative vocal cord paralysis to be independent predictors for RLN invasion.

Previous studies ${ }^{7,15,18,19}$ have indicated that preoperative vocal cord paralysis occurred in approximately 35\%-70\% of patients with RLN invasion, and preoperative voice change occurred in about $30 \%$ of patients with preoperative vocal cord paralysis. In our present study, 28 of 105 patients $(26.7 \%)$ in the invasion group were confirmed to have preoperative vocal cord paralysis, and only $8(28.6 \%)$ of these 28 patients had preoperative voice changes $(28.6 \%)$. As shown in our study, preoperative vocal cord paralysis was independent predictor of RLN invasion, and we speculated this result was related to the innervated muscles of the RLN. Although preoperative voice changes only occurred in approximately one-third of patients with RLN invasion, and pressing against RLN can also lead to vocal cord paralysis in the absence of invasion, when combined with imaging examinations to evaluate thyroid and tumor size, preoperative vocal cord paralysis is also highly specific for diagnosing RLN invasion.

In this study, age greater than 45 years was a risk factor for RLN invasion. Our results were comparable with the studies of Chiang et $\mathrm{al}^{14}$ and Chan et $\mathrm{al}^{20}$ which reported that the presence of preoperative RLN paralysis for welldifferentiated thyroid cancer would appear to be associated with older age. However, some other studies indicated that age less than 45 years significantly increased the risk of progression, recurrence, and central LNM in PTC patients, and these difference results may be attributed to different sample sizes and different follow-up times.

Tumor's size and location is also related to RLN invasion. A larger tumor is more likely to occur with extrathyroidal extension and adjacent structure invasion, and tumors located in the posterior portion of the thyroid gland are more likely to occur with RLN invasion, which is related to the anatomical location between the RLN and the thyroid gland. In addition, the rate of cervical LNM was reported to range from $30 \%$ to $80 \%$ in PTC patients, ${ }^{21,22}$ and most of these occurred in central area, so that RLN could also be infiltrated by LNM. ${ }^{6}$

RLN has anatomic proximity to the upper aerodigestive tract. The researches of Chiang et $\mathrm{al}^{14}$ and Ji Won Kim et $\mathrm{al}^{19}$ indicated that in most PTC patients with RLN invasion, the upper aerodigestive tract was also invaded by neoplasms. Our study confirmed that extrathyroidal extension, esophageal extension, and tracheal extension were independent predictors of RLN invasion, which was consistent with previous reports. Besides, a study by Randolph ${ }^{7}$ indicated that the preoperative identification of vocal cord paralysis in a patient without previous cervical surgery was $70 \%$ sensitive and nearly $100 \%$ specific for invasive thyroid cancer, and two other studies ${ }^{5,23}$ reported that the cause of death in PTC was related to uneradicated local disease in 36\%-47\%. Therefore, for diagnosed PTC, preoperative vocal cord 
paralysis indicates a high possibility of invasive thyroid cancer. In this case, the surgeon should perform additional imaging examinations (such as computed tomography scan or magnetic resonance imaging) to evaluate the extent of tumor invasion. A more extensive resection and a more careful operation are also needed.

The prognosis is also a very important aspect for group comparison. In our study, we found that the postoperative complications were not different between the two groups, and this may be attributable to the experience of the surgeons; the studies of Conzo et $\mathrm{al}^{24}$ and Gambardella et $\mathrm{al}^{25}$ also reported similar results, which indicated sufficient extensive resection was important to reduce recurrence rate in thyroid carcinoma, and at the same time, standardized operation and abundant surgical experience were the keys to reduce surgical morbidities. Additionally, we found that the length of postoperative hospital stay in the RLN invasion group was longer than in the control group, and the overall hospitalization costs in the invasion group were greater than in the control group. This phenomenon could be explained by the following reasons: as mentioned previously, patients with RLN invasion often have invasion of other adjacent structures, which may require a more extensive resection. In some rare instances, prophylactic tracheotomy would be implemented when the surgeon is unsure of the functional status of bilateral RLN. All of these situations can lead to longer postoperative hospital stays and greater hospitalization costs.

Our study showed that the recurrence rate was higher in the invasion group than in the control group. This result is similar to those of several other studies..$^{5,12,26,27}$ Our study also found that in the invasion group, there were no differences in recurrence rate between patients in whom the nerve were resected and patients in whom the nerves were preserved. Studies by Falk et al, ${ }^{9}$ Kim et al, ${ }^{19}$ Nishida et al, ${ }^{27}$ also reported similar results. In other words, patients with RLN invasion may have a higher recurrence rate, but the preservation or resection of RLN may not influence the ratio of recurrence. So in these cases, surgeons should have a higher sense of responsibility to carefully separate the RLN from the tumor rather than simply cut it away, which may helps to retain the function of the RLN.

There are several limitations in our study. First, this study was retrospective and the control group was randomly selected, which may lead to selection biases. Second, the mean follow-up time was only 32 months. Finally, the single-center nature of the study may have limited our analysis. More multicenter studies are needed to verify our findings.

\section{Conclusion}

Most of patients with RLN invasion always have a negative prognosis and a higher recurrence rate. Age greater than 45 years, a largest tumor size bigger than $10 \mathrm{~mm}, \mathrm{cN} 1$, posterior focus, extrathyroidal extension, esophageal extension, tracheal extension, and preoperative vocal cord paralysis were independent predictors for RLN invasion. These factors should alert the surgeon to the need to evaluate the extension of tumor invasion more comprehensively, and a more extensive resection, a more careful operation, and a more meticulous follow-up are also needed.

\section{Acknowledgments}

The first authors of this manuscript are Wenjie Chen and Jianyong Lei. Both authors contributed equally to this study and should be considered as co-first authors. This research did not receive any specific grant from funding agencies in the public, commercial, or not-for-profit sectors. No benefits in any form have been received or will be received from a commercial party related directly or indirectly to the subject of this article.

\section{Author contributions}

Wenjie Chen and Jianyong Lei performed research and wrote the first draft. All authors contributed toward data analysis, drafting and revising the paper and agree to be accountable for all aspects of the work.

\section{Disclosure}

The authors report no conflicts of interest in this work.

\section{References}

1. Lim H, Devesa SS, Sosa JA, Check D, Kitahara CM. Trends in thyroid cancer incidence and mortality in the United States, 1974-2013. Jama. 2017;317(13):1338-1348.

2. Pacini F. Changing natural history of differentiated thyroid cancer. Endocrine. 2012;42(2):229-230.

3. DeSantis CE, Lin CC, Mariotto AB, et al. Cancer treatment and survivorship statistics, 2014. CA Cancer J Clin. 2014;64(4):252-271.

4. McCaffrey JC. Aerodigestive tract invasion by well-differentiated thyroid carcinoma: diagnosis, management, prognosis, and biology. Laryngoscope. 2006;116(1):1-11.

5. McCaffrey TV, Bergstralh EJ, Hay ID. Locally invasive papillary thyroid carcinoma: 1940-1990. Head Neck. 1994;16(2):165-172.

6. Moritani S. Impact of lymph node metastases with recurrent laryngeal nerve invasion on patients with papillary thyroid carcinoma. Thyroid. 2015;25(1):107-111.

7. Randolph GW, Kamani D. The importance of preoperative laryngoscopy in patients undergoing thyroidectomy: voice, vocal cord function, and the preoperative detection of invasive thyroid malignancy. Surgery. 2006;139(3):357-362.

8. Farrag TY, Samlan RA, Lin FR, Tufano RP. The utility of evaluating true vocal fold motion before thyroid surgery. Laryngoscope. 2006; 116(2):235-238. 
9. Falk SA, McCaffrey TV. Management of the recurrent laryngeal nerve in suspected and proven thyroid cancer. Otolaryngol Head Neck Surg. 1995;113(1):42-48.

10. Kihara M, Miyauchi A, Yabuta T, et al. Outcome of vocal cord function after partial layer resection of the recurrent laryngeal nerve in patients with invasive papillary thyroid cancer. Surgery. 2014;155(1):184-189.

11. Haugen BR, Alexander EK, Bible KC, et al. 2015 American Thyroid Association Management Guidelines for adult patients with thyroid nodules and differentiated thyroid cancer: The American Thyroid Association Guidelines Task Force on Thyroid Nodules and Differentiated Thyroid Cancer. Thyroid. 2016;26(1):1-133.

12. Shah JP, Loree TR, Dharker D, Strong EW, Begg C, Vlamis V. Prognostic factors in differentiated carcinoma of the thyroid gland. $\mathrm{Am} \mathrm{J}$ Surg. 1992;164(6):658-661.

13. Price DL, Wong RJ, Randolph GW. Invasive thyroid cancer: management of the trachea and esophagus. Otolaryngol Clin North Am. 2008; 41(6):1155-1168, ix-x.

14. Chiang FY, Lin JC, Lee KW, et al. Thyroid tumors with preoperative recurrent laryngeal nerve palsy: clinicopathologic features and treatment outcome. Surgery. 2006;140(3):413-417.

15. Chiang FY, Wang LF, Huang YF, Lee KW, Kuo WR. Recurrent laryngeal nerve palsy after thyroidectomy with routine identification of the recurrent laryngeal nerve. Surgery. 2005;137(3):342-347.

16. Gupta J, Varshney S, Bist SS, Bhagat S. Clinico-etiolological study of vocal cord paralysis. Indian J Otolaryngol Head Neck Surg. 2013;65(1): 16-19.

17. Takashima S, Takayama F, Wang J, Kobayashi S, Kadoya M. Using MR imaging to predict invasion of the recurrent laryngeal nerve by thyroid carcinoma. AJR Am J Roentgenol. 2003;180(3):837-842.

18. McCaffrey TV, Lipton RJ. Thyroid carcinoma invading the upper aerodigestive system. Laryngoscope. 1990;100(8):824-830.
19. Kim JW, Roh JL, Gong G, et al. Treatment outcomes and risk factors for recurrence after definitive surgery of locally invasive well-differentiated papillary thyroid carcinoma. Thyroid. 2016;26(2):262-270.

20. Chan WF, Lo CY, Lam KY, Wan KY. Recurrent laryngeal nerve palsy in well-differentiated thyroid carcinoma: clinicopathologic features and outcome study. World J Surg. 2004;28(11):1093-1098.

21. Shaha AR, Shah JP, Loree TR. Patterns of nodal and distant metastasis based on histologic varieties in differentiated carcinoma of the thyroid. Am J Surg. 1996;172(6):692-694.

22. Wada N, Duh QY, Sugino K, et al. Lymph node metastasis from 259 papillary thyroid microcarcinomas: frequency, pattern of occurrence and recurrence, and optimal strategy for neck dissection. Ann Surg. 2003;237(3):399-407.

23. Tollefsen HR, Decosse JJ, Hutter RV. Papillary carcinoma of the thyroid. A Clinical And Pathological Study of 70 fatal cases. Cancer. 1964;17:1035-1044.

24. Conzo G, Avenia N, Ansaldo GL, et al. Surgical treatment of thyroid follicular neoplasms: results of a retrospective analysis of a large clinical series. Endocrine. 2017;55(2):530-538.

25. Gambardella C, Tartaglia E, Nunziata A, et al. Clinical significance of prophylactic central compartment neck dissection in the treatment of clinically node-negative papillary thyroid cancer patients. World J Surg Oncol. 2016;14(1):247.

26. Friedman M, Danielzadeh JA, Caldarelli DD. Treatment of patients with carcinoma of the thyroid invading the airway. Archiv Otolaryngol Head Neck Surg. 1994;120(12):1377-1381.

27. Nishida T, Nakao K, Hamaji M, Kamiike W, Kurozumi K, Matsuda H Preservation of recurrent laryngeal nerve invaded by differentiated thyroid cancer. Ann Surg. 1997;226(1):85-91.
OncoTargets and Therapy

\section{Publish your work in this journal}

OncoTargets and Therapy is an international, peer-reviewed, open access journal focusing on the pathological basis of all cancers, potential targets for therapy and treatment protocols employed to improve the management of cancer patients. The journal also focuses on the impact of management programs and new therapeutic agents and protocols on

\section{Dovepress}

patient perspectives such as quality of life, adherence and satisfaction. The manuscript management system is completely online and includes a very quick and fair peer-review system, which is all easy to use. Visit http://www.dovepress.com/testimonials.php to read real quotes from published authors. 